\title{
Inspirations for the Ideological and Political Education in College from Confucius' Life Wisdom
}

\author{
Nai-fang Zhang ${ }^{1}$, Dong-sheng Zhang ${ }^{2}$ \\ ${ }^{1)}$ College of humanities, North China Electric Power University, Baoding,Hebei, China \\ ${ }^{2)}$ Department of Foreign Language, North China Electric Power University, Baoding,Hebei, China
}

\begin{abstract}
In Confucius' ideological system, there are many logical and clear contents on life education, which have many life wisdom. Benevolence is fundamental in our life, which means we should try our best to do things what we should do, and we mustn't do things what we shouldn't do. To practice Benevolence is pleasant. They all can help us to teach our college students in the ideological and political education from contents and methods.
\end{abstract}

Keywords - Confucius, life wisdom, the ideological and political education

\section{孔子生命智慧对高校思想政治教育的启示}

\author{
张乃芳 $^{1}$ 张冬生 $^{2}$ \\ 1) 华北电力大学政教部，保定，河北，中国 \\ 2) 华北电力大学外语系, 保定, 河北, 中国
}

摘 要 孔子思想体系中有逻辑严密、层次清晰的生命教育内容, 蕴含了丰富深刻的生命智慧。其中, 以“仁”为本, 有所作为是人 生之本; 有所不为, 知“耻”所在, 是人生之限; “仁”“乐”相和则是人生之境。这些生命智慧对我们现在的大学生思想政治教育有教育 内容和方法上的重要启示。

关键词 孔子，生命智慧，思想政治教育

\section{1. 引言}

孔子是我国古代重要的思想家、教育家, 他的许多思 想对我们现在的教育仍然有重要的启迪作用。孔子的学说 中饱含了丰富的对人生的思考, 人生应当怎样度过, 如何 富含价值, 追求怎样的人生境界等问题, 他都进行了深刻 的思考, 并将自己的价值理念以各种不同的但又恰当的方 式传达给学生, 实现了因材施教的生命教育, 蕴含了丰富、 深刻的生命智慧。

\section{2. 孔子生命智慧的内容}

孔子的生命智慧可以从以下三个方面来看, 即人生之 本、人生之限和人生之境。

保定市哲学社会科学规划研究项目 (资助号: 2014BD0103)

\section{1 以“仁”为本的有所作为的人生}

孔子的思想博大精深，涉猎广泛，其思想体系从“仁” 出发, 以“仁”为核心。成功的人生必是“成仁”的、“合道” 的, 正如孔子所说: “志于道, 据于德, 依于仁, 游于艺。” (《论语·述而第七》) 朱喜解释说: “盖学莫先于立志, 志道, 则心存于正而不他; 据德, 则道得于心而不失; 依仁, 则 德性常用而物欲不行; 游艺, 则小物不遗而动息有养。学 者于此, 有以不失其先后之序、轻重之伦焉, 则本末兼该, 内外交养, 日用之间, 无少间隙, 而涵泳从容, 忽不自知 其入于圣贤之域矣。”[1]“仁”是为学、为人的根本所依。

“仁”不是外在于人的, 而是内在的、在已的, 这一观 点, 孔子曾多次对自己的弟子传达。《论语》开篇就说: “人 不知而不愠, 不亦君子乎? ”(《论语. 学而第一》) 君子不以 
他人的不解、甚至误会而生气, 这当然是修养问题, 是君 子高德的体现, 但能做到这一点, 君子必不将对自我评价 的标准放在他人身上, 而是要自我把握, 也就是说, 生命 价值的标准不在人而在已、不在外而在内。这个内在的标 准就是“仁”。所以孔子说: “仁远乎哉? 我欲仁, 斯仁至矣。” （《论语·述而第七》）欲“仁”则“仁”至, 因为“仁”本不远, 是本心之“仁”, 无需外求。“不患无位, 患所以立; 不患莫 己知, 求为可知也。” (《论语. 里仁第四》) 君子务本, 求内 在的“成仁”的根本。

“仁”的内在性并不意味着自我封闭, “仁”不是不可言 说、不可分享、不求共通的私我体验, 它寻求沟通, 通过 恰当处理人与人之间的关系寻找生命体验的共通之处。“不 患人之不己知, 患不知人也。” (《论语. 学而第一》) 也就是 说, 君子重自知, 也重知人。“知人”不同于“为人”。孔子区 分了古今学者的不同, 他说: “古之学者为己, 今之学者为 人。” (《论语. 宪问第十四》) “为己”之学目的是提高自己内 在的仁, “为人”之学则为在他人那儿展现自己的智, 前者 为的“成仁”, 后者意图“显智”。可见, “知人” 是对自知的补 充和延伸, 是有益的; “为人” 是将标准让渡于外, 是伤害 仁的内在性的。

“仁”不是单独的、抽象存在的, 行“仁”之道正是通过由 内在本心推向外在他心实现的。如曾子所说: “夫子之道, 忠恕而已矣。” (《论语. 里仁第四》) “忠” 是要顺本己之心, “恕” 则是要知他心, 是顺着了解本心的思路, 推己及人。 “忠”、“恕”正是孔子思想体系中一以贯之的内义。实现“忠 恕”之道的现实落点就是血缘亲情, 所以有“君子务本, 本 立而道生。孝弟也者, 其为仁之本与” (《论语. 学而第一》) 的说法。仁不是空洞的博爱词汇, 而是在社会群体生活中 体验到的人与人的情感, 蕴含了丰富、真实的现实生命感 悟。

“仁”的内在性决定了孔子坚持行仁之道的坚定性。有 隐士晨门评价孔子是“知其不可而为之者” 《论语. 宪问第十 四》), 其间充满了嘲讽之义。楚狂接與也讱讽孔子的不识 时务, 说“风兮! 凤兮! 何德之衰? 往者不可谏, 来者犹可 追。已而, 已而! 今之从政者殆而! ”(《论语·微子第十八》) 言风在有道之时见, 无道之境隐, 孔子能见不能隐, 这是 德衰的体现, 两者都主张逃世为更高的选择。孔子周游列 国寻求行仁道的可能, 却屡屡受挫, 他自己也说“天下有道 则见, 无道则隐” (《论语·泰伯第八》), 慨叹过归隐, 说: “归 与! 归与! 吾党之小子狂简, 斐然成章, 不知所以裁之。” (《论语. 公冶长第五》), 甚至还曾心灰意冷地宣称: “道不 行, 乘桴浮于海。从我者由与? ” (《论语. 公治长第五》), 不仅要避世, 连一同避世的人选都考虑了。理想不得实现 的困境的确给了孔子不小的打击, 退隐不失为一个避免困
境的选择, 但是, 还要看到, 孔子提出子路陪同“乘桴浮于 海” 的建议之后, 孔子又说 “由也好勇过我, 无所取材” (《论 语. 公冶长第五》), 以无所取材为借口, 否定了自己之前避 世远游的提议。面对长沮、桀溺等避世之人的诘难, 他更 言明 “鸟兽不可与同群, 吾非斯人之徒与而谁与? 天下有 道, 丘不与易也。” (《论语. 微子第十八》) 避世而居, 当然 可以避免理想与现实的冲突, 回避困境, 但正是因为天下 无道, 他才更需要尽己之力。人生天地间, 有自己不可推 卸的使命, 所以说, “人能弘道, 非道弘人。” (《论语. 卫灵 公第十五》) 他的弟子子路领悟了夫子的精神, 指出: “君 子之仕也, 行其义也。道之不行, 已知之矣。” (《论语· 微 子第十八》) 行内在之义, 行内在之仁, 才真正合乎于道。 孔子用自己的实际行动诠释了仁道践行的内在之义。

\section{2 以“耻”为限的有所不为的人生}

有所作为不是无所不为, 而是和有所不为相辅相成的。 孔子多次运用了耻感教育, 在不同的情境中因人而异地教 导学生划定道德行为的底线。这不是离开 “仁”, 而是从不 同的角度丰富“仁”的内涵。

“仁”不是模糊、甚至抹杀是非, 相反是明辨是非。孔 子说: “唯仁者能好人, 能恶人。”(《论语. 里仁第四》) 子 贡问孔子: “乡人皆好之, 何如? ”孔子回答说: “未可也。” “乡 人皆恶之, 何如? ”孔子也说: “未可也。不如乡人之善者 好之, 其不善者恶之。” (《论语. 子路第十三》) “当为”还是 “不当为”, 依据的还是“仁”。

孔子对学生的耻感教育中, 有对“宰予昼寝” (《论语. 公 冶长第五》) 的严厉批评, 批评宰予说: “朽木不可雕也, 粪土之墙不可朽也, 于予与何诛。” (《论语. 公治长第五》)。 短暂有限人生当中, “昼寝”不是简单的懒惰的问题, 而是 对“有为”人生理想的放弃, 是与“仁”道实现背道而驰的, 所 以, 孔子的批评几乎是毫不留情的。

不论是不是自己的学生, 孔子发现不合“仁”的现象, 都会表达自己的是非选择。如孔子批评季氏: “八佮舞于庭, 是可忍也, 勍不可忍也” (《论语.八佮第三》), 面对远离“仁” 道的原壤, 孔子不仅批评他: “幼而不孙弟, 长而无述焉, 老而不死, 是为贼! ”, 还“以杖吒其胫” (《论语. 宪问第十 四》), 令其行合“仁”之礼。

孔子“邦有道, 贫且贱焉, 耻也; 邦无道, 富且贵焉, 耻也” (《论语.泰伯第八》) 的观点, 将个人的贫富与邦国的 荣辱紧密结合, 言明了不同情形下, 有为无为的取舍。追 求富贵的现实利益, 同样不能伤害“仁”, 要合“仁”, 他说: “富与贵是人之所欲也, 不以其道得之, 不处也; 贫与贱是 人知所恶也, 不以其道得之, 不去也。君子去仁, 恶乎成 
名? 君子无终食之间违仁, 造次必于是, 颠沛必于是。”(《论 语. 里仁第四》) 如果“仁”与“利”冲突, 孔子会选择前者, 他 说: “不义而富且贵, 于我如浮云。” (《论语·述而第七》) 君子不是一定要追求贫贱, 而是要不以贫贱为意, “君子谋 道不谋食。耕也, 馁在其中矣; 学也, 禄在其中矣。君子 忧道不忧贫。”(《论语. 卫灵公第十五》) 一旦将重心放在外 在之利上, 就会远离“仁”道, 所以说: “土志于道, 而耻恶 衣恶食者, 为足与议也。”(《论语·里仁第四》)

\section{3 “仁”“乐”相和的人生}

孔子的人生是“仁”“乐”相和的, 他说: “不仁者不可以 久处约, 不可以长处乐。仁者安仁, 知者利仁。” (《论语. 里 仁第四》)

在“仁”与“利”产生矛盾的时候, 无论是孔子还是颜回都 毫不犹豫地选择了“仁”, 并且以此为乐, 所以 《论语》中 有“饭疏食饮水, 曲肱而枕之, 乐亦在其中矣。不义而富且 贵, 于我如浮云” (《论语·述而第七》) 和“贤哉, 回也! 一 笔食, 一漂饮, 在陃巷。人不堪其忧, 回也不改其乐。贤 哉, 回也” (《论语·雍也第六》) 的记载。

\section{3. 对高校思想政治教育的启示}

孔子的教育不拘泥于抽象的理论, 而是因时、因事、 因人而异, 他的生命智慧对我国大学生思想政治教育的有 多方面的影响。

内容方面的影响: 在校大学生正处于从家庭走向社会 的过渡阶段。大学之前, 他们的主要的精力都放在学习上,
学什么、不学什么的选择权主要由学校安排。进入社会后, 他们将自己面对诸多做什么、不做什么一类的选择, 如何 选择、以什么为选择标准是他们必须学习的。在当今价值 多元化的社会里, 选择的标准也呈现出了多样性。在这样 的背景下, 大学校园对学生的思想政治教育需要引导学生 建立健康的主流价值观。

孔子生命智慧中的“有所作为”和“有所不为”相互支撑、 相互诠释, 可以引导大学生对生命价值、尊严的思考, 帮 助学生理解社会主义核心价值观, 从而有助于他们不断反 省自己的价值立场, 实现对自己社会主义核心价值观的培 育和践行。

孔子生命智慧“仁”、“乐”相和的境界, 有助于引导学生 建立乐观面对和实现自己理想的愿望和信心, 热爱生命、 珍惜生命, 积极乐观创建生命的价值。

方法方面的影响: 孔子的教育不是僵硬的, 而是活泼 的、个性化、因人而异的, 确确实实做到了因材施教, 我 们的思想政治教育也应该秉持同样的原则, 针对不同的学 生采取恰当的方式, 学会倾听学生内心的声音, 从而激发 内在于学生心中的正能量, 同时为其能量的发挥创建良好 的环境与条件, 使思想政治教育真正做到有的放矢。

\section{参考文献(References)}

[1] Zhu Xi, The four chapter focus, Changsha: Yuelu Publishing House, 2007, pp.129. 